\title{
Factors Influencing Zimbabwean Physiotherapy Students in Choosing Physiotherapy as a Career
}

\begin{abstract}
People join professions for different reasons and the same applies to physiotherapists. The aim of the study was to identify the reasons for choosing physiotherapy as a career by Zimbabwean physiotherapy students. The study used a descriptive cross-sectional design where a questionnaire was administered to 60 students. Data were collected on the demographics of the students and also on their rating on the importance of 12 factors for their influence in them choosing physiotherapy as a career.

Three factors, which were, "the results I obtained at 'A' Level" (68\%), "job availability"(67\%) and "desire to help others"(60\%), were rated by more than $60 \%$ of the students as factors that had been "very important" in

\section{Mkondo T, BSc PT'; \\ Mudzi W, MSc PT'; Mbambo NP, MPHST $^{2}$}

${ }^{1}$ University of Zimbabwe, Faculty of Health Sciences, Rehabilitation Department, Harare, Zimbabwe.

2 University of the Witwatersrand, Faculty of Health Sciences, Physiotherapy Department, Johannesburg. South Africa. their decision to pursue physiotherapy as a career. Two factors, "I always wanted to be a physiotherapist" and "I worked with or received treatment from a physiotherapist", were the only factors, which were rated by more than $70 \%$ of the students as no important in the students' decision.

Using the paired t-test, no significant statistical differences were found between male and female students, in their rating of importance of all twelve factors, ( $p$-value $=0.01)$.
\end{abstract}

\section{KEY WORDS: CAREER CHOICE, PHYSIOTHERAPY, PHYSIOTHERAPY STUDENT.}

In Zimbabwe currently, there is a shortage of physiotherapists to serve the population. This shortage is compounded by the migration of qualified physiotherapists to developed countries. More than eighty percent of doctors, nurses, and therapists who graduated from the University of Zimbabwe medical school since independence in 1980, have gone to work abroad, primarily in Britain, Australia, New Zealand, Canada and United States (Mail and Guardian, 2003). The harsh economic situation in the country has resulted in many people, professionals and non-professionals, looking for ways to leave the country. Physiotherapists are no exception and one does wonder if there may be some

\section{CORRESPONDENCE TO:}

\section{Witness Mudzi}

University of the Witwatersrand

Faculty of Health Sciences

Physiotherapy Department

Conacher Block,

7 York Road, Parktown 2193

Johannesburg, South Africa

Tel: (011) 717-3710/3716

Fax: (011) 717-3719

Email: witness.mudzi@wits.ac.za physiotherapy students who chose to enter the programme for economic gains.

Since the inception of the physiotherapy degree in Zimbabwe in 1987, more males have graduated from the programme than females (Statistics from Department of Physiotherapy, University of Zimbabwe 1987-2003). Since Short (1986) proposed that physiotherapy is a predominantly feminine profession, the Zimbabwe phenomenon raises an interest on why the male students choose physiotherapy as a career. If students or practicing health professionals are misplaced in their professions because of wrong career choices, they often find themselves suffering dissonance, high anxiety or both, (Hardigan and Cohen, 1998). In extreme cases the person may opt to leave the profession altogether to pursue a career more befitting them, (Nordhalm and Westbrook, 1985; Mbambo, 2002).

Several longitudinal studies on reasons for career choice amongst physiotherapy students have been conducted over the years in Canada, Sweden and recently South Africa, (Ohman et al., 2001; Ohman et al., 2002; Mbambo 2002). These studies have highlighted some of the major reasons for career choice including job accessibility; a desire to help and work with people; an interest in sports and athletic injuries and previous knowledge of the profession, (Ohman et al., 2001; Ohman et al., 2002; Mbambo, 2002). It was interesting to find out if these reasons would hold true for Zimbabwean physiotherapy students as similar studies in Zimbabwe have not been conducted to date. To that effect, a survey which included all Zimbabwean physiotherapy students from the first to the fourth years of the programme in the 2003-2004 University of Zimbabwe calendar year was done.

\section{LITERATURE REVIEW}

The literature that was reviewed outlined the theories of career development to provide a background to factors influencing career choice and the reasons for career choice identified in the past.

Over the years, several theories have been developed in an attempt to explain a person's reasons for choice of career. All of the theories can be used to explain a person's preferred choice of career. In many instances more than one theory can apply. Since these are theories, some were developed a long time but are still relevant and so will be reviewed. 


\section{Psychoanalytic Theory}

Anne Roe (1956) came up with a psychoanalytical theory that looked at the influence of childhood experiences on occupational choice. She believed that early childhood experiences were strongly related to occupational choices and that personality could be the most important factor in career choice. She described three psychological climates that affect the work that one eventually chooses to pursue: an over protective or over demanding atmosphere; a neglectful or rejecting atmosphere; and a loving and relaxed environment. Roe proposed that one was likely to choose a career that reflected the psychological climate in which they had grown up. When simplified, her theory predicts that children who grow up in a loving and relaxed environment will tend to choose professions that relate to people such as teachers, social workers, church workers etc. This theory however fails to account for those people who do not conform to it and the theory itself is now old.

\section{Trait-Factor Theory}

Holland's theory (1997) of occupational choice also known as the Trait-Factor Theory suggested that vocational choice is an expression of one's personality and it reflects the person's motivation, knowledge, and ability. In essence, individuals are attracted to a particular occupation that meets their personal needs and provides them satisfaction. Two of his assumptions were that a) individuals may be categorized as belonging to one or two of six personality types: Realistic, Investigative, Artistic, Social, Enterprising and Conventional, based on their personality type and b) an individual will then choose an environment that will let them exercise their skills and abilities, attitudes and values, and take on agreeable problems and roles.

Holland's theory thus implies that it is important for individuals to know their personality types to avoid choosing an occupation that will not meet their personal needs or provide them with satisfaction. A strong criticism of this theory is based on gender bias because females tend to score higher in three personality types (artistic, social and conventional) which Holland attributes to societal channelling of females into female-dominated professions.

\section{Developmental Theories}

Developmental theories arose in the 50's in opposition to the Trait-Factor Theory that was viewed as being static in that it implied, "one choice and you're satisfied for life". Developmental theories in contrast view career choice as a longterm process. This process dictates that all individuals progress through life in specific stages that have critical developmental tasks necessary for making a good career choice. Two prominent developmental theories used today are Super's (1963) Self-concept theory and Ginzberg et al.'s (1951) developmental theory.

Ginzberg (1951) et al. viewed career choice as a long-term developmental process, which was influenced by four factors: the reality factor, the influence of the educational process, the emotional factor and individual values. This developmental process, starting in preteen and ending in young adulthood, involved three stages; fantasy, tentative and realistic. An individual has to go through all three stages until a career choice is made. During the realistic stage, a child selects his choice based on his personal likes, skills and abilities then he pursues the educational experiences required for achieving his career goal.

This theory has its limitation in that it does not account for those people who find themselves changing careers in later life and its assumption that all children go through the stages in chronological order appears to be too rigid.

Super (1963), not only viewed career choice as a long-term developmental process, but as an unfolding process and not a point in time event. His view was that selecting a career is a process that progresses and recycles through five stages, and which is also determined by socioeconomic level, mental ability, personality and opportunities. The five stages are; growth (childhood years), exploration (teens-early adulthood), establishment (early-mid-adulthood), maintenance (mid-late-adulthood) and disengagement (late adulthood).

The Self-concept theory proposes that, people differ in ability, personality, needs, values, interests and traits (in one word self-concept). Super recognized that the self-concept changes and develops with time and experience, making career choice and adjustment a continuous process. It is during the exploration stage, that individuals go through trial experiences in their careers or areas of interest so that they can decide whether they want to pursue that career or move on to something else that is better for them.

Despite the fact that some researchers have strengthened some of the theories through their results (Perrone et al., 2002; Tsuda et al., 1982), the applicability of the theories to women, people of color, and other socioeconomic groups has been called into question (Kerka, 1998). This was because some of the prevailing career development theories have been based solely on research on white males from middle- and uppermiddle-class backgrounds. This fact alone would make it difficult for one to generalise these research findings to the student population used for this study as it was mostly made up of black students of middle-to lower class background.

\section{Factors influencing career choice}

In reviewing the literature it was noted that only one research by Mbambo (2002) has been conducted on a totally African/Black population to date. Other studies involving physiotherapy students were conducted on non-African, predominantly white populations, [Ohman et al. (Sweden), 2001; Ohman et al. (Canada), 2002; Brown-West (America), 1991]. There is also an apparent difference in the duration of the physiotherapy programmes offered in other countries from the four-year training programme in Zimbabwe. Canada offers a two-year programme, (Ohman et al., 2002), while Sweden's is three years (Ohman et al., 2001). These differences could make it difficult to generalise findings of these studies to the Zimbabwean physiotherapy students.

Considering that there are a countless number of possible reasons or factors that could influence one's selection of a career, four factors that have been identified in similar student populations through literature review are outlined below. These are knowledge of the 
profession, job availability, view of the profession and income and prestige.

Knowledge of the profession was highlighted by Tsuda et al. (1982) as a valid and important factor to consider in career choice. The South African study conducted by Mbambo in 2002, looked at the reasons for career choice, and the type, and source of knowledge that black first-year physiotherapy students from six different universities had, prior to enrolling into the degree programme at their respective universities. Results indicated that black physiotherapy students chose physiotherapy due to the influence of the previous knowledge they had of the profession (65\%). This knowledge had been accumulated through exposure to career guidance classes and personal contact with a physiotherapist before coming to university. Fifty eight percent of the South African students in Mbambo (2002)'s study had been influenced by the "prospects of finding a job on completion of their studies". Ohman et al (2002)'s research results were in agreement with Mbambo's findings in that a quarter $(25,5 \%)$,of their Canadian physiotherapy students had cited "job accessibility" as one of their main reasons for choosing a career in physiotherapy.

How a particular profession is viewed in a given society may influence one's career choice either positively or negatively. In 1986, Short proposed that physiotherapy, being a predominantly feminine profession, was attractive to middle and upper class women with traditional values as it provided the opportunity for private practice work and hence more opportunities for parttime work. This premise was reflected by the dominance of females in Ohman et al's studies in Sweden (2001) (75\% women, $25 \%$ male; $\mathrm{N}=187)$ and in Canada (2002) (72\% women, $28 \%$ male; $\mathrm{N}=40$ ). Ohman et al. (2001)'s study also revealed that $65 \%$ of the students had a middle class background while only $20 \%$ had a working class one.

Although success and happiness in a given profession are often defined in terms of monetary wealth and recognition or respect given to one by other persons, it is interesting to note that in Mugonzibwa et al.'s study (2000), few of the participants mentioned "high earnings" or "prestige" as reasons for career choice. Ohman et al's results (2001) reinforced the lack of importance of income in career choice. Contrasting findings in 1991 by Brown-West, and later in 2002 by Ohman et al. had "income potential" as an important factor in career choice of their samples (80.2\% N=91 Brown-West, 1991; 25.5\% N=40 Ohman et al., 2002). Pearl (1990), noted that income as an influencer of career decision becomes most important in older practicing physicians (Mean age $=33.7$ years). It was interesting to note in a study conducted by Perrone et al. (2001) that whereas men anticipated earnings as a major influence on career goal setting, women based their long-term career goals on prestige of the occupation.

Very little research has been done on African and/or the minority populations of physiotherapy students, which makes it difficult to generalize the findings from past researches discussed in the review to this particular study. Therefore, these findings have explained the need to conduct this study in Zimbabwe and also illustrated the relevance that the findings could have to the profession.

\section{Study Aim}

The aim of the study was to identify the reasons/factors that influence students in their selection of Physiotherapy as a career choice and evaluate whether there was a gender difference in factors influencing students to choose Physiotherapy as a career .

\section{METHODOLOGY}

This was a descriptive cross-sectional survey which targeted all the Zimbabwean physiotherapy students from the first to the fourth years of the programme in the 2003-2004 University of Zimbabwe calendar year.

A self-administered questionnaire comprising both open and closed-ended questions was used for data collection. The second section of the questionnaire (which is the thrust of this paper) looked at twelve factors that can influence career choice. Most of the factors provided in the list were obtained from a similar list used by Brown-West (1991) on Allied Health Students. Brown-West (1991) calculated the reliability coefficient of her factor-section as seventy eight percent. Other options were included after the pilot study had identified other factors that had not been listed. Students were approached at the end of a lecture and an explanation on the research, voluntary participation was stressed and instructions were given. Those who consented to taking part in the research were allowed fifteen minutes to complete the questionnaire whereupon they submitted the completed forms, submitted face down to the researcher's assistants at the front of the lecture room. For confidentiality, students were asked not to write their names anywhere on the questionnaire. This procedure was repeated for all the four groups of physiotherapy students.

\section{RESULTS}

Data was captured and analyzed using the Epi-2000 programme. Descriptive analysis was done using frequencies and a paired t-test was done to establish the difference between male and female responses.

\section{Response Rate}

The total number of registered and eligible students for the research within the programme in the 2003-2004 academic year was 65. Sixty-two students filled in the questionnaires. Two questionnaires were discarded as they had more than one error in them and therefore 60 of these were analyzed. A response rate of $92 \%$ was achieved.

\section{Demographic Data}

The mean age of the respondents was 22 years. The youngest student was nineteen and the oldest was 39 years old. Ninety-five percent of the students were 25 years old or under. Thirty two (53\%) respondents were males and $28(47 \%)$ were females.

\section{Factors Influencing Career Choice}

The students were requested to rate in order of importance, 12 factors which influenced them in deciding to pursue a career in physiotherapy. Not all the students rated all the factors therefore the totals of responses differ. The results are illustrated in Table 1 and are presented in order of the students' ranking. 
Most of the students (60\% and above) rated number of points obtained at A' level, job availability and desire to help other people as very important for deciding on physiotherapy as a career. Two factors were rated as not important in the career decision of more than $70 \%$ of the students and these factors were "I always wanted to be a physiotherapist" and "I worked with/ received treatment from a physiotherapist" (90\%).

The highly ranked factors were further analyzed according to gender. A T-test was carried out to test the following hypotheses:

Table 1: Illustration of the ranking of importance of factors which influenced the decision to pursue physiotherapy as a career.

\begin{tabular}{|l|l|l|l|}
\hline Factors & \multicolumn{3}{|c|}{ Importance } \\
\hline & $\begin{array}{l}\text { Very } \\
\mathrm{n}(\%)\end{array}$ & $\begin{array}{l}\text { Fairly } \\
\mathrm{n}(\%)\end{array}$ & $\begin{array}{l}\text { Not } \\
\mathrm{n}(\%)\end{array}$ \\
\hline The number of points I had at A' level & $\mathbf{4 1 ( 6 8 )}$ & $10(17)$ & $9(15)$ \\
\hline Job availability & $\mathbf{4 0 ( 6 7 )}$ & $13(22)$ & $7(11)$ \\
\hline Desire to help other people & $36(60)$ & $19(32)$ & $5(8)$ \\
\hline Failure to secure a place in other degree & $29(48)$ & $6(10)$ & $25(42)$ \\
\hline Interest in sports and athletic injuries & $29(48)$ & $17(28)$ & $14(24)$ \\
\hline Potential to earn a good salary & $29(48)$ & $20(34)$ & $10(17)$ \\
\hline Flexible work schedule & $23(38)$ & $27(45)$ & $10(17)$ \\
\hline Professional status/ prestige of profession & $20(33)$ & $25(42)$ & $15(25)$ \\
\hline Opportunity to interact with people & $18(30)$ & $24(40)$ & $18(30)$ \\
\hline Opportunity to use own initiative & $18(30)$ & $27(46)$ & $14(24)$ \\
\hline I always wanted to be a physiotherapist & $4(7)$ & $13(21)$ & $43(72)$ \\
\hline $\begin{array}{l}\text { I worked with/ received treatment from } \\
\text { a physiotherapist }\end{array}$ & $4(7)$ & $2(3)$ & $53(90)$ \\
\hline
\end{tabular}

$\mathrm{H}_{0}$ : There is no difference in rating of factor between male and female students.

$\mathrm{H}_{1}$ : There is a difference in rating of factor between male and female students.

Accept $\mathrm{H}_{1}$ if $\left(\mathrm{t}_{\text {stat }}>+\mathrm{t}_{0.01}\right)$ or if $\left(\mathrm{t}_{\text {stat }}<\right.$ - $\mathrm{t}_{0.01}$ ) reject $\mathrm{H} 0$

The results are illustrated in Table 2.

Although there is a difference in numbers of the ranking by male and female students, there was no statistical difference in the ranking between males and females. This is explained by the $\mathrm{t}_{\text {stat }}$ being smaller than $+\mathrm{t}_{0.01}$ thus accepting the $\mathrm{H}_{0}$.

Table 2: Illustration of ranking by gender.

\begin{tabular}{|l|l|l|l|l|l|l|}
\hline Factors & \multicolumn{2}{l|}{ Importance } & T - test & \\
\hline & Very Important & \multicolumn{2}{l|}{ Not important } & $\mathbf{t}_{\text {statistic }}$ & $\mathbf{t}_{\mathbf{0 . 0 1}}$ \\
\hline & $\begin{array}{l}\text { Male } \\
\mathbf{N}=\mathbf{3 2}\end{array}$ & $\begin{array}{l}\text { Female } \\
\mathbf{N}=\mathbf{2 8}\end{array}$ & $\begin{array}{l}\text { Male } \\
\mathbf{N}=\mathbf{3 2}\end{array}$ & $\begin{array}{l}\text { Female } \\
\mathbf{N}=\mathbf{2 8}\end{array}$ & \\
\hline The number of points I had at A' level & $23(72)$ & $18(64)$ & & & -0.57 & \pm 9.92 \\
\hline Job availability & $23(72)$ & $17(61)$ & & & -0.41 & \pm 9.92 \\
\hline Desire to help other people & $17(53)$ & $19(68)$ & & & -0.66 & \pm 9.92 \\
\hline $\begin{array}{l}\text { I always wanted to be } \\
\text { a physiotherapist }\end{array}$ & & & $23(72)$ & $20(72)$ & -1.51 & \pm 9.92 \\
\hline $\begin{array}{l}\text { Worked with/ received treatment } \\
\text { from a physiotherapist }\end{array}$ & & & $28(91)$ & $25(89)$ & -0.65 & \pm 9.92 \\
\hline
\end{tabular}


were found using the paired t-test. This result mirrors that of Ohman et al (2002) who reported that they had not found any statistically significant differences in the reasons given for career choice among male and female physiotherapy students.

\section{FACTORS INFLUENCING CAREER CHOICE: Number of points obtained at A level}

In Zimbabwe there is a shortage of Universities training medical students to serve the population. In an effort to overcome the problem of selection for various degree programmes, a high number of points achieved at A' Level has been used as the main entry requirement. With this in mind, it stands to reason why most students would rank the number of points achieved at A' Level" as most important in their career decision. No comparable findings were found in the literature. As a result, this finding is unique to this population of Zimbabwean physiotherapy students.

If the Super's (1963) career development theories is considered, it can be somewhat related to this finding. In the five development stages that he proposes, exploration stage seems to be the one that these students are at in terms of the choice of A Level points. The exploration stage is further supported by the fact that the factor of 'always wanted to be a physiotherapist' was ranked as not important by $72 \%$ of the students. Exposure to physiotherapy was also ranked as not important by most of the students $(90 \%)$. These rankings suggest that the students do not know physiotherapy and that they are exploring the profession. Super's (1963) view was that selecting a career is a process that progresses and which is also determined by socioeconomic level, mental ability, personality and opportunities.

\section{Job Availability}

The second factor rated by sixty seven percent of the physiotherapy students influencing their career choice was "job availability". This revealed that the prospects of finding a job after graduation were an important factor in the career choice of the physiotherapy students. Other researchers (Mbambo, 2002 and Ohman et al, 2002) obtained similar findings.
With the high inflation and unemployment rates currently being experienced in Zimbabwe, this finding is reasonable as most people in the country are now looking for job availability and security. These physiotherapy students obviously considered socioeconomic situation and opportunities in their selection of career. As they develop in the physiotherapy profession they may remain in the profession or change the profession if this career was exploratory or other financial prospects present themselves.

\section{Desire to help other people}

Sixty percent of the students in the present study rated "desire to help other people" as a very important factor that influenced their decision to pursue a career in physiotherapy which placed this factor third in the order of importance of the factors. Although $70 \%$ of the students reported that the "opportunity to interact with people" was an important factor in the career choice, only $30 \%$ rated it as a "very important" factor in their career choice. Hence, this factor was ninth in the order of importance. This is a rather odd result as it suggests that although the Zimbabwean physiotherapy students want to help people through physiotherapy, they are not however as keen to interact with them. An inference of this could be that the students are only interested in people when they are sick in the hope of helping them to get better.

Roe's psychoanalytic theory (1956) of career choice can be applied and an extrapolation be made that most Zimbabwean physiotherapy students grew up in loving family environments where their personal growth was encouraged by loving and supportive parents. As a result of this nurturing environment, a desire to help other people through appropriate means such as physiotherapy, was cultured which influenced these students to select Physiotherapy as a career. Although this explanation is possible, no empirical evidence was found in the literature that supported this theory. As a result, it would be necessary to conduct a full research looking into the influence of family background on the career choice of
Zimbabwean physiotherapy students for one to use this explanation confidently.

\section{Previous knowledge of the profession}

From the results, a large proportion of students $(90 \%)$ rated previous exposure to the profession obtained through working with or receiving treatment from a physiotherapist as "not important" in their decision of career choice. Similarly, $72 \%$ of the students rated "I always wanted to be a physiotherapist" as "not important". These results are in contrast with Tsuda et al' (1982) who found that knowledge of the profession is a valid and important factor to consider in career choice and Mbambo's (2002) results which found that students chose physiotherapy due to the influence of the previous knowledge they had of the profession.

This raises a question of where or how the students got to know about the profession prior to applying for a place in the programme. In interacting with fellow physiotherapy students, it was noted that some students reported that they had never heard of the physiotherapy profession up until the day they came to pay for the application form required for a place in a degree programme offered at the University of Zimbabwe. These students "discovered" the existence of physiotherapy when they saw it listed as one of the degrees offered by the university in the application form. Having seen it they then proceeded to seek more information about the programme from friends and relevant literature. This further strengthens the theory that these students were at Super's (1963) exploration stage of career development.

Ledgered (2001) found that among Occupational Therapy (O.T.) students, $81 \%$ of them had spent time observing O.T. practice or worked with an OT prior to entering the programme. $\mathrm{He}$ also noted that although Non-Caucasian students as a whole were less likely to have been exposed to the profession in this manner, African students were the most likely Non-Caucasian race to not have observed O.T. practice than any other group. Although the students used in this study were O.T. students, the results of this present study are comparable to theirs, as the black (African) 
students in this study also appear to lack practical exposure to the profession prior to entering the programme.

\section{Income and prestige of the profession}

The "potential to earn a good salary" $(82 \%)$ as well as "the status or prestige of the profession" (75\%) were viewed as important factors in the career choice of the physiotherapy students. However, the aspect of income was considered "very important" by $49 \%$ of the students and the prestige of the profession by $33 \%$. This placed the two factors in the 6th and 8th positions in the order of importance of factors.

The importance placed on income by the Zimbabwean physiotherapy students is in agreement with the findings of Brown-West (1991) and Ohman et al. (2002) . Gender differences reported by Perrone et al. (2001), where they found that males tended to select income as more important over prestige than females, were not found to be significant at 0.01 level $(\mathrm{p}<0.01)$ in this study.

One would have thought that, with the high inflation and unemployment rates currently being experienced in Zimbabwe, income would have been closer to job availability in the ranking of importance. Then again, if unemployment is high, people may be satisfied to have a job even if the salary is not high. Desire to help other people could be the influencing factor here more than the income itself.

\section{CONCLUSIONS}

It has been noted that currently there is a shortage of physiotherapists in Zimbabwe, to serve the population. This shortage is compounded by the migration of qualified physiotherapists to developed countries. If the factors that influence students to choose physiotherapy as a profession are considered against the career development theories a concern can be raised of whether the students would remain in the physiotherapy profession. In other words, would they add to long term physiotherapy human resource needs of Zimbabwe?

There are career development theories that seem to be linked to this population of Zimbabwe students but there is no clear linkage. Kerka, (1998) had called into question the applicability of the career development theories to women, people of colour, and other socioeconomic groups. The question was raised because some of the prevailing career development theories had been based solely on research on white males from middleand upper-middle-class backgrounds. Recent theories need to be explored.

Although the results of this research do not add new information to the practice of physiotherapy profession per se, they indicate a need to ensure exposure of prospective students to the physiotherapy profession. The exposure could ensure that after qualifying, the students would remain in the profession. The results also indicate a need to begin to explore racial differences in different spheres of education and learning. Race is a sensitive topic but in research it serves to dispel or confirm perceptions, and to understand different students' educational needs.

\section{REFERENCES}

1. Australian Statistics (1999) 8552.0 Females dominate physiotherapy profession. (Media Release) Last updated 12-09 00. http://www.abs.gov.au/Ausstats/abs@.nsf/ 0/FFB7673A229000BECA2568A90013634E ?OPEN

2. Brown-West A.P. (1991) Influencers of career choice among Allied Health studentsJournal of Allied Health, Summer; 181-189.

3. Ginzberg E., Ginsburg S.W., Axelrad S., Herma J.L. (1951) Occupational Choice: an approach to a general theory- New York; Columbia University Press.

4. Hardigan P.C. and Cohen S.R. (1998) Comparison of personality styles between students enrolled in Osteopathic medicine, Pharmacy, Physical Therapy, Physician Assistant, and Occupational Therapy programmes - Journal of the American Osteopathic Association (J.A.O.A.); 98 (11): 637-641.

5. Holland J.L. (1997) Making vocational choices: a theory of vocational personalities and work environments-Psychological assessment resources, Odessa (3rd edition).

6. Kerka S. (1998) Career development, gender, race and class- Eric Digest no.199 http://www.ericfacility.net/databases/ ERIC_Digests/ed421641.html
7. Ledgered R. (2001) To be or not to be? - Factors Influencing the career choice of Occupational Therapy Studentshttp://www.baot.co.uk/public/publications/int ro/tobe/ToBe.pdf.

8. Mail and Guardian (2003) Brain drain hits Zimbabwe's health service - Southern African Migration Project (SAMP), August 28. http://www.queensu.ca/samp/news/2003/ aug.htm

9. Mbambo N.P.(2002) Factors influencing black students in choosing physiotherapy as a career-(Not yet published) University of Witwatersrand South Africa.

http://www.wcpt.org/common/doc/wcpTTues Thurs.pdf

10. Mugonzibwa E.A., Kikwilu E.N., Rugarabamu P.N., Ntabaye M.K. (2000) Factors influencing career choice among high school students in Tanzania- Journal of Dental Education, June; 64 (6): 423-9

11. Nordhalm L.A. and Westbrook M.T. (1985) Career development of female physiotherapists: stage four of a longitudinal surveyThe Australian Journal of Physiotherapy; 31 (1): $10-16$.

12. Ohman A., Solomon P., Finch E. (2002) Career choice and professional preferences in a group of Canadian physiotherapy studentsAdvances in physiotherapy; 4: 16-22.

13. Ohman A., Stenlund H., Dahlgren L. (2001) Career choice, professional preferences and gender-the case of Swedish physiotherapy students- Advances in physiotherapy; 3: 94-107.

14. Pearl M.J. (1990) Factors physical therapists use to make career decisions- Physical Therapy; 70 (2): 105-107.

15. Perrone K.M., Sedlack W.E. and Alexander C.M. (2001) Gender and ethnic differences in career goal attainment Career Development Quarterly; December http://www.findarticles.com/cf_dls/m0JAX/2_ 50/81762551/p1/article.jhtml

16. Perrone K.M., Zanardelli G., Worthington Jr. E.L., Chartrand J.M. (2002) Role model influence on the career decidedness of college students- College Student Journal, March.

17. Roe A. (1956) The psychology of occupations, New York, Wiley.

18. Short S.D. (1986) Physiotherapy-a feminine profession- Australian Journal of Physiotherapy; 32 (4): 241-243.

19. Statistics from the Department of Physiotherapy University of Zimbabwe- Total numbers and gender of Physiotherapy students since 1987 to 2003.

20. Super D.E. (1963) Career Development: Self Concept Theory- College Board.

21. Tsuda H.C., Kiser B.C., Shepard K.F. (1982) Factors influencing high school students' knowledge of physical therapyPhysical Therapy; 62 (8): 1157-1164. 